Western University

Scholarship@Western

2017

International Service-Learning: Rethinking the Role of Emotions

Marianne A. Larsen

Western University, mlarsen@uwo.ca

Follow this and additional works at: https://ir.lib.uwo.ca/edupub

Part of the Education Commons

Citation of this paper:

Larsen, Marianne A., "International Service-Learning: Rethinking the Role of Emotions" (2017). Education Publications. 154.

https://ir.lib.uwo.ca/edupub/154 


\title{
International Service-Learning: Rethinking the Role of Emotions
}

\author{
Marianne A. Larsen
}

\begin{abstract}
Existing research on international service-learning (ISL) only implicitly alludes to emotions or considers emotions as a limited vehicle through which the more important work of learning occurs. This study set out to shift this focus on emotions to show how emotions are an integral part of the overall ISL experience. The aim was to understand how an ISL internship was an emotional experience for the student participants through the lens of noncognitive process theory of emotions. This was a qualitative case study of the experiences of 10 university students who engaged in an ISL internship in East Africa. Data collection instruments included preinternship surveys and emotional mind maps, postinternship surveys, and interviews. The study demonstrated that ISL can be a highly charged, emotional experience for student participants. The author argues that emotional responses are not simply a limited catalyst through which learning and transformation transpires, but constitutes forms of understanding in and of themselves. This points to the need for ISL researchers and practitioners to shift their preconceptions about the value of emotions in learning and transformation processes and attend to the emotional dimensions of ISL in their research and the implementation of these programs.
\end{abstract}

\section{Keywords}

international service-learning, emotions, higher education

Much has been written about the positive outcomes associated with international service-learning (ISL). Some researchers, for example, have directed their attention to the ways in which ISL promotes learning through reflective thinking processes (e.g., Ash, Clayton, \& Moses, 2007; Boyle-Baise, 2002; Bringle \& Hatcher, 1999; Eyler \& Giles, 1999; Hartman, 2008; Kiely, 2005; King, 2004). In this body of research, emotion, as a part of philosophical foundations of service-learning, is largely viewed as "the trigger for the intellectual work of reflection" (Felten, Gilchrist, \& Darby, 2006, p. 40). In this article, I shift the focus from emotions as a vehicle by which transformation occurs in ISL participants, to emotions as a central outcome of ISL experiences. In other words, I suggest that we begin the work of privileging the emotional outcomes of ISL as valuable in and of themselves, and not simply as catalysts or vehicles toward other more rational or intellectual transformative forms. In this way, I am building on Felten et al.'s (2006) argument to suggest that researchers focus on the emotional dimension of ISL not solely as a limited component of the more important reflective learning process, but as an integral part of the overall ISL experience.

No aspect of our mental life is more important to the quality and meaning of our existence than emotions. Emotions are considered as noncognitive processes that involve the affective appraisal of situations and events, a physiological response, and cultural labeling of that response (e.g., anger, happiness) (J. Robinson, 2005). From ancient philosophers onward, many have argued that emotions are crucial for human well-being, decision making, motivation, and even our basic survival. As Rosenberg (1990) emphatically states, "The importance of the emotions both for the individual and for the society can scarcely be overestimated. ... Emotions are matters of profound concern to everyone" (p. 4). Indeed, emotions are the epitome of what makes us human.

This article is based on a case study of 10 university students who engaged in a long-term ISL internship in East Africa between 2013 and 2014. Taking up Tonkin's (2011) call for ISL research on emotions, the focus of the study was on understanding the emotional dimension of service-learning in international contexts. I begin by outlining my theoretical framework, the noncognitive process theory of emotions. I review the small body of literature that addresses the emotional dimensions of service-learning. I then describe the methodology and background for the case study, which is followed by a review and discussion of the key findings of the study. In contrast to Deweyian-inspired approaches that posit emotions simply as vehicles to the more important cognitive work of reflection and action, I argue that emotional experiences in ISL are a form of understanding in and of themselves, and that emotions provide the data for reflection and interpretation, which are as much emotional acts as they are rational. 


\section{Theoretical Framework: Noncognitive Process Theory of Emotions}

There are basically three categories of emotional theories: evolutionary, social, and process. Evolutionary theories, drawn from Darwin's work, attempt to explain why emotions are present in humans today by referring to natural selection that occurred in the past. The social approach views emotions as the products of societies and cultures, and are acquired or learned by individuals through experience. Although proponents of this approach acknowledge that emotions are, to some degree, natural phenomena, the main argument is that emotions are best understood from a social constructivist perspective (e.g., Averill, 1980).

The process (or internal) approach focuses on the emotion process, which begins with the perception of a stimulus and the triggering of the bodily response (e.g., changes in heart rate, blood pressure, facial expression). Within the process approach, there are a number of different theories. Cognitive theorists contend that the early part of the emotion process includes the manipulation of information, and so, should be understood as a cognitive process (Johnson, 2015). The judgment theory emphasizes the role of thought in the genesis of emotion and the way emotions follow from the way individuals appraise or judge events, matters, or incidents deemed important to them. In this respect, emotions involve personal and moral evaluative judgments about one's own desire, values, interests, and goals, and these processes are cognitive. In other words, without a judgment, there can be no emotion (Solomon, 1976).

However, it is the noncognitive theories of emotions that frame the theoretical framework for my study. Noncognitive theories do not view judgments or appraisals as part of the emotion process, but rather that the emotional response directly follows the perception of a relevant stimulus. Therefore, instead of a judgment about the stimulus, the early part of the emotion process is thought to be reflex like and, in this way, noncognitive theories view emotions as separate from the rational or cognitive operations of the mind. Emotional responses are considered a set of physiological responses and, contrary to the judgment theory, evaluation may not even be a necessary precondition for emotions (J. Robinson, 2005).

There are two different noncognitive approaches. The first develops an explanation of the noncognitive process, but claims that only some emotions are noncognitive. The second approach describes the noncognitive process in a similar way, but defends the idea that all emotions are noncognitive (Johnson, 2015). It is this second approach that forms the theoretical framework and justification for the basis of this study.

Drawing upon the work of the philosopher Jenefer Robinson (2005), I consider the main process in any emotionprovoking situation to be primarily noncognitive (i.e., emotional) with cognitive processes an additional element. According to this line of thought, emotion is considered a process involving a judgment. J. Robinson rejects the judgment theory of emotion noting that however we describe the relevant judgment, it is always possible to make the judgment (e.g., I have been wronged), but not feel the corresponding emotion (e.g., anger). She points out that there are cases of emotion that do not require a conscious complex appraisal as judgments theorists contend. However, some kind of judgment or evaluation is essential to emotion and Robinson calls this "affective appraisals," which are fast and automatic. These appraisals or judgments are emotional, occurring "below the threshold of cognition" (J. Robinson, 2005, p. 41), and thus not requiring higher order thinking skills. This notion of noncognitive appraisal, which shifts the discussion about the role of cognition in emotion, is central to this study. In other words, I do not view emotions as simply the vehicle to the more important, rational work of reflection and interpretation, but rather, I view emotional experiences themselves as forms of understanding, wholly embedded through the learning and transformation processes associated with experiential education.

\section{Literature Review}

Many have traced the theoretical roots of service-learning first to Dewey's (1933) philosophies of experience, inquiry, and reflection to Kolb's ideas of experiential education. Kolb built upon Dewey's conclusion that learning is a holistic affair, linking together emotions and the intellect, to construct a model for the learning cycle, in which individuals move from feeling, to observing, to thinking, to doing (Eyler \& Giles, 1999; Stanton, Giles, \& Cruz, 1999). Plater (2011) has outlined how the intellectual foundation for service-learning lies in Dewey's ideas about education as engaged experience, and specifically that learning occurs within the lived experience of communities. However, it is not only experience that leads to learning, but reflection as the necessary connection between experience and theory. Experience, as Bringle and Hatcher (1999) explain, "becomes educative when critical reflective thought creates new meaning and leads to growth and the ability to take informed actions" (p. 180). Above all, less attention is directed toward the emotional over the rational domain, as emotions are valued only as a catalyst to the more important process of rational thought. 
ISL has also been heavily influenced by the ideas associated with Dewey (1933) and other experiential educators (e.g., Ash et al., 2007; Bringle \& Hatcher, 1999; Eyler \& Giles, 1999; Kiely, 2005). Dewey's philosophy of learning emerges from Western, positivist traditions that privilege reason above emotion. According to Dewey (and those who subscribe to his philosophies), emotion plays an important but limited role in the reflection process, which is viewed as essentially a rational act (Felten et al., 2006). For example, in their seminal text on service-learning, Eyler and Giles (1999) reflect upon how amazed they have been by how "the emotional power of service-learning helps students connect intellectually with what we were doing in the classroom" (p. 19), and they quote a student in their study who says, "I think people will do more thinking once they have felt" (p. 195) This type of reasoning leads Felten et al. (2006) to redefine reflection in service-learning as a process "involving the interplay of emotion and cognition in which people (students, teachers, and community partners) intentionally connect service experiences with the academic learning objectives" (p. 42).

There is a small, but growing, body of literature on the potential of service-learning and ISL to enhance students' emotional development. A number of studies focus on the sometimes-painful emotions resulting from "critical incidents" (Mezirow, 1991) or "forked-road" situations (Dewey, 1933), experienced during service-learning, which then lead to transformational processes of self-change (e.g., Holmes, 2015; Kiely, 2004, 2005). Other studies emphasize the positive emotions generated by service-learning experiences. Dahms (1994) asserts that multicultural service-learning is an effective means of helping students develop their "emotional comfort zones" (p. 93) in learning about diversity. Other studies have focused on the development of care, compassion, and empathy as emotional outcomes of ISL and service-learning (Eyler \& Giles, 1999; Kiely, 2005; King, 2004; Sedlak et al., 2003). Some researchers propose that service-learning has the potential to foster empathy and compassion in multicultural contexts that help to bridge the divide between "us" and "them" (Boyle-Baise, 2002). Moreover, much of this research suggests that the emotions of empathy and compassion motivate humans to act and, therefore, are a precondition to civic action (e.g., Astin, Vogelgesang, Ikeda, \& Yee, 2000; DeGenaro, 2010; Kiely, 2004).

Langstraat and Bowdon (2011) point out that empathy and compassion are likely the most frequently referenced emotions in service-learning publications. In their article on service-learning and critical emotion studies, they assert the need for service-learning students and community members to consciously engage in analyses of emotional hegemony. Their review of service-learning literature shows that compassion and empathy are undertheorized or uncritically characterized as unmitigated goods and automatic outcomes. Empathy, they argue, is too often thought of as an unspoken objective of service-learning, while "the judgment-to-action feature of compassion is muted" (p. 8). Indeed, Langstraat and Bowdon (2011) call for service-learning pedagogies that denaturalize emotionality to "reach compassion's politics in service-learning pedagogy and theory" (p. 13).

Fostering compassion in service-learning involves confronting unequal power relations between students and members of their host communities. Some researchers have drawn our attention to the uncomfortable feelings that arise for service-learning students as they grapple with new knowledge associated with White and socioeconomic power and privilege (Camacho, 2004; Dunlap, Scoggin, Green, \& Davi, 2007; Green, 2001). In this literature, these difficult emotions are viewed as a part of the concientization process through which service-learning participants become aware of their own privilege(s) and begin the hard work toward reforming unequal power relations.

This limited body of research on emotions and service-learning reviewed above suggests the need for further empirical studies to understand the emotional aspects of ISL and service-learning. This study aimed to fill that gap in the literature, noted by ISL researchers such as Kiely (2005) and Tonkin (2011). As DeGenaro (2010) asserts, "it's essential that service learning practitioners wrestle with the notion of emotion, if only because so much emotion surrounds service learning work" (p. 216).

\section{Method}

This was a case study of the experiences of 10 university students who engaged in an ISL internship in East Africa. Case study is "a study of a bounded system, emphasizing the unity and wholeness of that system, but confining the attention to those aspects that are relevant to the research problem at the time" (Stake, 1988, p. 258). The students received course credit for participating in service-learning internships as a part of a Canadian university project, North Goes South (NGS), to set up community-based, microenterprise kitchens in East Africa. NGS was established in 2004 by a Canadian university, in partnership with a local Tanzanian nongovernmental organization (NGO), as the university's response to the HIV/AIDS crisis in Africa. ${ }^{1}$ Today, the project involves many individuals in Tanzania, Rwanda, and Kenya, including the women who work in the kitchens, lab technicians, and those who work at local partner organizations.

This particular study is based on the 2013-2014 cohort of two male and eight female students who participated in $N G S$ internships lasting between 2 and 6 months. The service component of their internship was based on their 
academic program. For example, students from the Business School engaged in service related to marketing strategies and business plans for the microenterprise kitchens. Health sciences students engaged in service related to the production of the milk-based product made in the kitchens.

I drew upon four data sources to answer the following research question:

Research Question 1: How is ISL an emotional experience for students?

The data collection instruments included a preinternship survey and emotional mind maps, and a postinternship survey and interview. On the presurvey, students were asked to indicate the emotions they felt about going to East Africa. Upon their return, they completed the same exercise. The presurvey included questions about the challenges/barriers that they thought they would face, which I followed up on during the postinternship interviews. During the interviews, participants were probed about how the internship was emotional for them, including the emotional dimension of critical incidents. When asked about their emotions, most students discussed the feelings they experienced. Feelings are understood in this study as a subjective representation of emotions, private to the individual experiencing them. In other words, feelings are the thoughts we have after emotions occur, and for that reason, they are considered evidence of emotional responses.

Together, the visual emotional map, pre-and post-survey, as well as interview data were triangulated during the analysis stage of this study. By drawing upon a variety of data-gathering sources and methods, I deployed "multi-method triangulation approach" (Patton, 2012). Multimethod triangulation occurred through the analysis and cross-verification of the different data sources to locate regularities and patterns in the data, enhancing the concurrent validity of the study. The analysis process also involved the identification of categories and themes generated by the data sources to provide more robust meaning to understanding the emotional dimensions of ISL.

\section{Findings \\ Emotions Before Departure}

Before their departure for East Africa, most of the students felt very or extremely curious, excited, enthused, and interested to be participating in this internship. There was a sense of great excitement and enthusiasm about going to East Africa. All 10 of the participants included the words "excited" or "excitement" on their emotional mind maps, some in very large letters. Most also indicated that they were feeling confident, purposeful, focused, empowered, enthused, and engaged. Other "positive" words used on the emotional mind maps included hopeful, thrilled, and happy. A number of students (four) expressed a sense of privilege and gratitude for having being chosen to participate in the internship. They used words such as special, worthy, lucky, and fortunate to describe their emotions. Although a few interns indicated that they felt ready, prepared, focused, and confident prior to departure, the rest (six) used words such as worried, apprehensive, anxious, and unprepared to describe their emotions.

On their mind maps, some of the students expressed worries, fears, and anxieties that they would miss their boy/girlfriends, husbands, children, friends, and other loved ones. Rhonda noted feeling "home-sick" and Edna was sad that she would miss her family and boyfriend. Lara drew a mountain with herself carrying a backpack comprised of her family, friends, and study homework, starting off at the foot of the mountain, visually depicting that she had the support she needed to undertake this journey. Indeed, she wrote on her mind map that her drawing is "an honest assessment of my thoughts at this moment ... It feels like a big mountain to climb."

\section{Emotions During the Internship}

Each of the students experienced a wide range of emotions during their internships. In their interviews, they talked about feeling happy, peaceful, and good during the experience. Most spoke about how much they enjoyed learning about other cultures. As one student explained, "I really, really enjoy Tanzanian culture and society. I think it was such a gift being someone who likes to learn and I'm trying to understand the social justice component of everything that's happening in Tanzania."

Many of the interns also talked about the sense of community and belonging that they experienced. Here, for example, are Edna's words about the people she met in Tanzania: "I did feel like I really belonged. Forming these relationships with these people. It was nice. There's a lot of times, walking around, I felt happy and peaceful." Others referred to feeling excited and adventurous, especially when they got off the "beaten path" and went on journeys outside of the communities in which they were based. Vera talked about her experiences traveling within Rwanda, noting that exploring these places made her feel adventurous and excited. And, once their research projects got 
underway, they spoke about the great sense of confidence, pride, and excitement they felt in having accomplished as much as they did during their experiences abroad.

However, although most students expressed a sense of pride and increased confidence due to personal successes working in challenging environments, they also experienced frustrations in trying to carry out their research and service. A number of the interns were frustrated by what they perceived to be as a lack of clear goals for their internships. Sam, in waiting for his project to move forward, felt a sense of uncertainty about whether the work he was doing there would lead to the intended outcomes. When asked how the experience was emotional for him, he responded,

I mean there's a number of emotions. Obviously I miss home, but that's not a big deal for me ... I guess one of the bigger ones is certainly the ambivalence of purpose that you have and whether it's having the intended consequences you want it to. That is something that comes up a lot because you're there and obviously there are things that you want to accomplish, because again you're dealing with complex problems, there's some uncertainty about whether what you're doing is actually leading to that or it's making things worse by creating dependency relationships.

Tina talked about a similar set of frustrations concerning the lack of understanding about her own role, and the absence of a common strategy and set of understandings among the various people and organizations associated with the community kitchens:

Everyone has their own thoughts and agendas ... so that's the most striking challenge. Everyone is communicating about different things all the time. There's no common strategy or goal. That was frustrating. I think I've blocked a lot of that out. That was an issue. Wires getting crossed all the time because ... within this one project there are many different goals.

The interns spoke about feeling isolated and lonely. As Lara who was based in Tanzania explained, "I do find that the urban setting in Mwanza does leave you a bit isolated unless you're really deliberate about making an appointment to go see someone." For some of the students, the sense of loneliness was stronger at the beginning of their internship before making friends and developing relationships. As Heidi described, "At first I was very lonely of course because it was a completely different culture and I was only there with one other person I met once or twice before, but didn't know that well." Barry, who was based in rural Kenya, explained how very sad and lonely he felt at the beginning of the internship as he was living in a secluded area in an apartment with one other intern. Similarly, Vera and Sam lived on the outskirts of Kigali, Rwanda, quite a distance from the city center and community kitchen where they worked during the day. Vera noted the "feelings of isolation" she felt, especially toward the end of her internship when Sam left and she was on her own.

Some students spoke about feeling scared for their own safety. They talked about their worries and fears about thefts, and in one case, a student had her money stolen from the apartment set up to accommodate interns based in Mwanza. During her postinternship interview, Tina talked at length about the theft and the emotions she felt:

I was so upset because there was some lead up to it and I was almost blaming myself. At the same time, my reaction to it, in hindsight, was not that appropriate. It was a mixed reaction because I was blaming myself, but I was also blaming other people. The circumstances were that night we went to the local food market to get something to eat. We were out for an hour. We come back. I didn't have my money locked and that's where I blame myself. I had it stuffed in a pouch hidden in the apartment, but not locked up. Then the following morning I discovered that it was gone. The only time period it could have happened was that previous night. I was so angry because there were other issues I was not aware of around dishonesty with people living in the apartment, not knowing who was living in the apartment, not knowing who had keys to the apartment, having several doors around the perimeter of the apartment with different locks on those doors and not being aware of any of this. Thinking this could have been prevented and so I was angry.

The word frustration came up a lot during the interviews especially with respect to what might be termed cultural differences. The students described a number of incidents that were upsetting for them, many involving long time delays and expectations not being met. Some students spoke about having to wait for long periods of time for others to show up for arranged meetings or get-togethers. Others spoke about the irritations involved in waiting for processes to move forward that affected their status in the country. Edna, for example, experienced unnecessarily long delays in trying to get her visa renewed, which caused her much stress and anger. After many weeks of waiting for the visa, she was informed that she would have to pay a US $\$ 600$ fine for her expired visa. She felt considerable anger toward the person who was supposed to have helped her with her visa renewal application and "burst out into tears because this [was] the last thing [she] wanted to hear at this point.” 
Many of the students experienced long delays and barriers in moving ahead with their research projects. One student "fell into a slump/depression," waiting for ethics approval to get her study started. Vera and Sam who were based in Kigali found that it took much longer than anticipated to get the community kitchen established there. After Sam left in July, the kitchen got up and running. However, Vera, who remained until August, experienced continued frustrations trying to move things forward to maintain operations with the kitchen. Edna who was researching the benefits of the nutritional supplement produced at the kitchens experienced difficulties and stress trying to conduct her study, such as participants not showing up and supplies running out. She expressed a sense of exasperation over an individual at the lab who interfered with her study and wrongly accused her of stealing some of the lab equipment. This was very upsetting, as she explained,

That made me feel really awful. I'm always making sure to be very careful especially with the situation with [Rex who said]_- “don't you trust me." I'm sorry, shouldn't it be a two-way street here? Why would I have any reason to lie to you about that? There's no reason for me. It might have more stemmed from the fact that I was a younger woman and this was an older man. I was very upset at him and I told him. Unfair.

All the participants commented on how they were called "mzungo" (White person) by local people. Being judged by the color of their skin was something the majority of the interns did not have experience with before and made them feel very uncomfortable. Some students expressed their annoyance over assumptions (held by "locals") that because the students were White, they were more privileged. This led to many instances of being asked for money or other resources that they did not feel that they had to give. In her interview, Edna talked about the feelings that arose for her in,

just being a white person there is stress. Even shopping, you know the prices of what things should be, but you'd go and ask someone the price for something and they would inflate it ten times of what it should be. After a while, you just get frustrated with it and you're like no, you're trying to charge me like a hundred or two hundred times the amount. So those were the frustrating aspects.

Rhonda also expressed her anger over the assumption that because she was White, she was privileged:

It was extremely frustrating. I'd be angry at times. I guess with the misunderstanding because they would expect so much from me, like on the monetary side, I'd feel guilty that I wouldn't be able to provide that for them, but mostly frustration because it didn't matter how much I would explain it, they would just see a white face and that means money to them.

The anxiety and anger that these students experienced in being called "mzungo" and being reminded of the privileges they embodied constitutes a prime example of a noncognitive approach to understanding emotions. Although they did not have the background knowledge, experience, and cognitive tools (e.g., theoretical constructs) to make sense of these difficult feelings, they were relying solely on their affective appraisals of each situation to make sense of it.

Finally, witnessing material forms of poverty, wide gaps between the rich and poor, as well as discrimination against the most vulnerable in society evoked emotions such as sadness, anger, and frustration in some of the students. In her blog, Vera, described a "very heartbreaking sight of seeing street children with glue bottles who hang outside of local shops." And Heidi, in reflecting upon her experience visiting a home for children with disabilities, explained how talking with the children and seeing their home "was very emotional for all of us." She continued, "[i]f someone can't contribute and is considered less than other people then they're not treated the same way, but it was definitely hard to see what they have gone through."

\section{Discussion}

This case study demonstrates that ISL can be a highly charged, emotional experience for student participants. Students, in this study, experienced a wide range of emotions immediately prior to and during the internship. In many ways, as one student stated, the internship was like "being on an emotional roller-coaster." There are many different ways to categorize the range of emotions that the students experienced immediately before and during their internships. Based on his review of theories of emotions, D. L. Robinson (2009) has identified and contrasted the fundamental "negative" and "positive" emotions. "Event-related" emotions include the positive emotions of hope, gratitude, and joy, and negative emotions of anger, sorry, and frustration. Students in my study experienced all these emotions. The event of departing evoked feelings of hope and optimism for the experience, as well as anxiety, nervousness, and fear. Various events that occurred during the internship (e.g., working in the community kitchens and meeting local people) induced not only positive feelings of 
gratitude and appreciation but also frustrations and even anger in some cases. The students also experienced positive "self-appraisal" emotions such as pride in their achievements, growing sense of self-confidence, purpose, and empowerment. However, although students did not speak explicitly about emotions "related to object properties" such as curiosity, admiration, and surprise, there was evidence that interns experienced these emotions during the internships. For example, many spoke about how impressed they were with hard work and resilience of the women who worked in the kitchens. Witnessing poverty contributed to feelings of sadness and in some cases, guilt, which D. L. Robinson (2009) claims are "social emotions."

What then is the relationship between these emotional experiences, reflection, learning, and, in some cases, transformation? I noted above that service-learning researchers who focus on emotions in their studies tend to reference Dewey and/or Kolb in their discussions about the transformative effects of service-learning or ISL. For Dewey and Kolb, reflection is a rational act and the limited role of emotion is to "catalyze scientific thought" (Felten et al., 2006, p. 38). Moreover, Mezirow's (1991) transformational learning theory, which has influenced much servicelearning research, "emphasizes the role of reflection in coming to terms with emotions" (Kiely, 2005, p. 16), and thus, privileges the rational domain over the affective. To reiterate, emotion has been conceptualized, in much of the existing ISL literature, as a vehicle leading to the more important rational work associated with reflection and action (e.g., Ash et al., 2007; Bringle \& Hatcher, 1999; Eyler \& Giles, 1999; Holmes, 2015).

In contrast, the noncognitive process theory of emotions provides an alternative framework for understanding the experience of emotions during ISL internships and shows how students' emotional responses are not simply a limited catalyst through which learning and transformation transpires, but the very foundation upon which understanding occurs. As Langstraat and Bowdon (2011) assert, “emotions, rather than 'spoilers' in practices of meaning-making that cloud judgment, are in fact integral to the development of critical consciousness" (p. 9). In other words, our emotional experiences are not just precursors to understanding, they are forms of understanding themselves.

Jenefer Robinson (2005) explains how this process works in her study of how emotion enters into our interpretations of works of art, literature, and music, how we learn emotionally from them about human nature and motivation, and how emotion manages and guides our responses to these works. First, we have an emotional response to the character (in the novel), piece of music, and so forth, followed by an affective appraisal of that response. This appraisal happens rapidly and does not necessitate a cognitive evaluation. Emotions felt (not just the rational thought that follows) demonstrate understanding, albeit an inarticulate form of understanding, which may lead to our ability to name the emotion. Physiological changes follow (e.g., heart beat increasing), and then a cognitive appraisal or monitoring of the situation, which includes judgments about the emotional response(s). J. Robinson (2005) claims that in addition to stimulating our interest in and attention to a work of art, literature, or music, our emotional responses "can also play a crucial role in the way we actually understand and interpret it" (p. 107). In other words, our emotions function in a way to alert us to important aspects of a story such as the setting and plot. Thus, we can see how emotions provide the data for interpretation and reflection, putting us in a better position to provide critical, interpretive accounts of our experiences. This shifts how we understand the relationship between the affective and the cognitive in servicelearning to focus on the continuous and intertwined interplay between emotional and cognitive processes of understanding (Felten et al., 2006).

We can see numerous examples of this above. In Tina's description of the theft of her money from her apartment, it is her emotional reactions to that episode that provide the data for her interpretation of the event. Similarly, Edna's description of the individual at the lab who angered her, shows us how her emotional response (anger, frustration) allowed her to make sense of the situation, as she tried to focus her attention on understanding from a gendered interpretation why she reacted in the way that she did. In another example, Heidi, a student intern in Kenya, described first how emotional it was for her to visit a home for "disabled children," and then, how she was beginning to understand that there are cultural differences in how peoples with disabilities are treated across contexts. In each of these cases, it is the felt emotions that guide students' learning as they interrogate their emotions to interpret their experiences.

These examples illustrate the limitations in assuming that learning and transformation only takes place through conscious cognitive processes. What J. Robinson's (2005) work points out is the importance of noncognitive (or affective) evaluations in the learning process. According to J. Robinson (2005), at their core, emotions involve noncognitive "instinctive" appraisals. Thus, the rational is not privileged over the affective. In fact, as the title of J. Robinson's (2005) book explains, emotions are "deeper than reason" in that they are triggered by an automatic affective appraisal and, thus, immune to cognitive assessment that is rational or irrational.

This is important when we address the emotions of compassion and empathy, which practitioners and researchers often view as key goals for service-learning experiences. Above, I reviewed a number of studies that attest to the fact that ISL has the potential to enhance compassion among student interns. Interestingly, when the students were asked to reflect upon the emotional dimension of their ISL internships, none of them spoke directly about feelings of compassion or empathy. However, there is evidence that the internship facilitated the development of dispositions 
associated with compassion. Seeing material inequalities and other inequities; becoming aware of their own privileges as (primarily) White, Western university students; and witnessing the resilience, optimism, and hard work among the women in the community kitchens created the conditions for students to develop compassion for their fellow human beings. For instance, Rhonda in reflecting upon the relationships that she developed during the internship said that "I feel like I made really strong bonds with a few of the women in the kitchen" and "I feel that the way we were impacted or changed for the better was in a way that we interacted with each other and learned about different cultures [italics added]." Such accounts, as well as their descriptions of the relationship and connections they developed with their East African hosts illustrate the compassion and sympathy they developed.

Kiely $(2004,2005)$ has written about the process of cognitive dissonance in his work on student transformation through ISL. He explains that dissonance occurs when individuals see, feel, hear, and participate in experiences that are new and incongruent with their existing worldviews. Kiely (2005) distinguishes between low- and high-intensity dissonance. The former consists of communication difficulties, adjustment to physical surroundings, transportation, housing, climate, and food. Students in my study did refer to these kinds of difficulties or challenges, but did not associate having emotional responses with them. Missing home was "no big deal" for Sam in comparison with other, more intense emotions that he experienced during the internship.

High-intensity dissonance, however, is much more complex and ambiguous. The examples Kiely (2005) draws upon to illustrate high-intensity dissonance among his student participants largely mirror those that I found in my study. For example, witnessing vast gaps of material wealth evoked feelings of sadness and shock among some (four) of the interns. Barry who visited rural areas in Kenya and the city of Nairobi noted sadly, "it was like two completely different ends of the spectrum." Other students spoke about how disturbed and upset they felt seeing the specific challenges faced by children living in poverty. Vera wrote about "the very heartbreaking sight" of seeing street children in Kigali with glue bottles who hang outside of local shops. And, as noted above, Heidi expressed how upset she was to witness the treatment of children living with disabilities. Kiely (2005) writes that high-intensity dissonance causes powerful emotions and confusion, leading participants to "re-examine their existing knowledge and assumptions regarding the causes and solutions to ambiguous and ill-structured problems such as extreme forms of persistent poverty" (p. 11).

There are two contributions I wish to make to Kiely's point about the role of emotion in the process of cognitive dissonance. First, rather than view dissonance as causing emotions, I would like to suggest that rapid noncognitive (affective) appraisals of a situation underpin the process of cognitive dissonance. The second and related point is that students may develop a cognitive awareness about the inequalities they witness during their sojourns abroad, but the affective appraisal may not evaluate this as worthy of an emotional response. In other words, and this is evident within my study, there were students who talked about the injustices they witnessed, but did not experience any emotion (e.g., sadness, anger) when reflecting upon these.

This illustrates the need for cognitive opportunities to unpack emotional experiences during and following ISL internships. Providing students with supports to make sense of the emotional dimensions of ISL means centering emotions in debriefing sessions, for example. I had to probe some students to reflect upon critical incidents that they may have "blocked out" or "shoved from their mind" due to the emotions that arose through such incidents. Providing students with safe and structured opportunities to make sense of their emotional experiences means that, first and foremost, we must begin to privilege how emotional responses play a crucial role in how we understand and interpret our experiences.

\section{Limitations and Conclusion}

This case study of 10 students who participated in a long-term ISL internship in East Africa demonstrates that ISL experiences have the propensity to arouse a wide range of emotions in students. The main limitation of this study concerns the small sample size, which critics argue makes it difficult to develop general propositions and theories. Yet, contrary to larger scale studies, the purpose of case study methodology is actually to provide an intensive, holistic description and analysis of a single, bounded unit situated in a specific context to provide insight into the complexities of social life. Indeed, the qualitative case study approach has several strengths to meet this broader goal, including the opportunity to establish rapport with research subjects, obtain sufficiently rich description that can be transferred to similar situations, and, ultimately, to develop in-depth insight into real-life situations (Cohen, Manion, \& Morrison, 2011; Merriam \& Tisdell, 2015). Moreover, following Flyvberg (2011), I contend that case study may be central to scientific development via generalization as a supplement to other methods. Hence, although I recognize the limits of this particular case study, I would argue that it points us toward a new direction for the role of emotions in future ISL studies. 
Connecting the many different theories about emotions is the idea that emotions matter. Indeed, it is widely accepted among many psychologists and philosophers that emotions are what it means to experience the world. Given how important emotions are not only to learning processes but also to our very being as humans, it is surprising that so little attention has been paid to the emotional dimension of ISL within the research literature. Although some of the research literature makes references to emotions, in most cases, the emotional dimension of ISL is only implicitly alluded to or emotions are viewed as a limited vehicle through which real learning occurs. In this respect, on the heels of the dominant positivist paradigm, the public domain of the rational is favored over the private realm of the emotional.

Nevertheless, many psychologists and philosophers have shifted our understanding of the affective domain. They view emotion as a crucial component of the thinking process and not simply a limited catalyst through which learning and action occurs. As J. Robinson (2005) explains with respect to the study of a novel, "responding emotionally is a form of understanding and that an interpretation, which claims to give an overall critical reflective understanding of novel as whole, is partly the result of reflection upon our emotional responses to the novel" (p. 124). What this means for ISL researchers is the need to attend very carefully to the emotional dimensions of service-learning in international contexts and the central role that emotions play throughout complex learning processes. And, most significantly, for those who plan and facilitate ISL programs, this alerts us to the urgent need to provide student participants with the tools to make sense of these emotion-laden experiences, and this necessitates shifting our preconceptions about the value of emotions in learning and transformation processes.

\section{Declaration of Conflicting Interests}

The author(s) declared no potential conflicts of interest with respect to the research, authorship, and/or publication of this article.

\section{Funding}

The author(s) received no financial support for the research, authorship, and/or publication of this article.

\section{Note}

1. The name of the university, the international service-learning (ISL) project, partners, and participants are all pseudonyms, and any identifying information has been removed to protect all identities.

\section{References}

Ash, S. L., Clayton, P. H., \& Moses, M. G. (2007). Teaching and learning through critical reflection: An instructors' guide. Sterling, VA: Stylus Publishing.

Astin, A., Vogelgesang, L., Ikeda, E., \& Yee, J. (2000). How service learning affects students. Los Angeles: Higher Education Research Institute, University of California, Los Angeles.

Averill, J. R. (1980). A constructivist view of emotion. In C. E. Izard (Ed.), Emotions in personality and psychopathology (pp. 339368). New York, NY: Plenum Press.

Boyle-Baise, M. (2002). Multicultural service learning: Educating teachers in diverse communities. New York, NY: Teachers College Press.

Bringle, R. G., \& Hatcher, J. A. (1999). Reflection in service learning: Making meaning of experience. Educational Horizons, 77, 179-185.

Camacho, M. M. (2004). Power and privilege: Community service learning in Tijuana. Michigan Journal of Community Service Learning, 10(3), 31-42.

Cohen, M., Manion, L., \& Morrison, K. (2011). Research methods in education (7th ed.). New York, NY: Routledge.

Dahms, A. (1994). Multicultural service learning and psychology. In R. J. Kraft \& M. Swadener (Eds.), Building community: Service learning in the academic disciplines (pp. 93-103). Denver: Colorado Campus Compact.

DeGenaro, W. (2010). The affective dimensions of service learning. Reflections: A Journal of Public Rhetoric, Civic Writing, and Service Learning, 9, 192-220.

Dewey, J. (1933). How we think: A restatement of the relation of reflective thinking to the educative process. Boston, MA: D.C. Heath.

Dunlap, M., Scoggin, J., Green, P., \& Davi, A. (2007). White students' experiences of privilege and socioeconomic disparities: Toward a theoretical model. Michigan Journal of Community Service Learning, 13(2), 19-30.

Eyler, J., \& Giles, D. (1999). Where's the learning in service learning? San Francisco, CA: Jossey Bass.

Felten, P., Gilchrist, L. Z., \& Darby, A. (2006). Emotion and learning: Feeling our way toward a new theory of reflection in servicelearning. Michigan Journal of Community Service Learning, 12(2), 38-46. 
Flyvberg, B. (2011). Case study. In N. K. Denzin \& Y. S. Lincoln (Eds.), Handbook of qualitative research (pp. 301-316). Thousand Oaks, CA: SAGE.

Green, A. (2001). "But you aren't White": Racial perceptions and service-learning. Michigan Journal of Community Service Learning, 8, 18-26.

Hartman, E. (2008). Educating for global citizenship through service-learning.:A curricular account and theoretical evaluation (Doctoral Dissertation). University of Pittsburgh: Pittsburgh, PA.

Holmes, A. J. (2015). Transformative learning, affect, and reciprocal care in community engagement. Community Literacy Journal, $9(2), 48-67$.

Johnson, G. (2015). Theories of emotion: The internet encyclopedia of philosophy. Retrieved from http://www.iep.utm.edu/emotion/\#SSH4b.ii

Kiely, R. (2004). A chameleon with a complex: Searching for transformation in international service-learning. Michigan Journal of Community Service Learning, 10(2), 5-20.

Kiely, R. (2005). Transformative international service-learning. Academic Exchange Quarterly, 9, 275-281.

King, J. T. (2004). Service-learning as a site for critical pedagogy: A case of collaboration, caring, and defamiliarization across borders. The Journal of Experiential Education, 26, 121-137.

Langstraat, L., \& Bowdon, M. (2011). Service-learning and critical emotion studies: On the perils of empathy and the politics of compassion. Michigan Journal of Community Service Learning, 17(2), 5-14.

Merriam, S. B., \& Tisdell, E. J. (2015). Qualitative research: A guide to design and implementation (5th ed.). San Francisco, CA: Jossey-Bass.

Mezirow, J. (1991). Transformative dimensions of adult learning. San Francisco, CA: Jossey-Bass.

Patton, M. (2012). Qualitative research and evaluation methods (3rd ed.). Thousand Oaks, CA: Sage.

Plater, W. M. (2011). The context for international service learning: An invisible revolution is underway. In R. G. Bringle, J. A. Hatcher, \& S. G. Jones (Eds.), International service learning: Conceptual frameworks and research (pp. 29-56). Sterling, VA: Stylus Publishing.

Robinson, D. L. (2009). Brain function, mental experience and personality. The Netherlands Journal of Psychology, 64, $152-167$.

Robinson, J. (2005). Deeper than reason: Emotion and its role in literature, music, and art. Oxford, UK: Clarendon Press.

Rosenberg, M. (1990). Reflexivity and emotions. Social Psychology Quarterly, 53, 3-12.

Sedlak, C. A., Doheny, M. O., Panthofer, N., \& Anaya, E. (2003). Critical thinking in students' service-learning experiences. College Teaching, 51(3), 99-103.

Solomon, R. C. (1976). The passions. Garden City, NY: Anchor Press/Doubleday.

Stanton, T. K., Giles, D. E., \& Cruz, N. I. (1999). Service learning: A movement's pioneers reflect on its origins, practice and future. San Francisco, CA: Jossey-Bass.

Tonkin, H. (2011). A research agenda for international service learning. In R. G. Bringle, J. A. Hatcher \& S. G. Jones (Eds.), International service learning: Conceptual frameworks and research (pp. 191-224). Sterling, VA: Stylus Publishing.

\section{Author Biography}

Marianne A. Larsen is an Associate Professor at the University of Western Ontario. Her research within the field of comparative and internationalization has focused most recently on various aspects of higher education internationalization. In addition to her research on international service learning, she has published on the broader practices associated with internationalization in higher education settings, theorizing these practices through spatial, mobility and network theories. 